NBER WORKING PAPER SERIES

\title{
THE IMPACT OF TRADE ON INTRAINDUSTRY REALLOCATIONS AND AGGREGATE INDUSTRY PRODUCTIVITY: A COMMENT
}

Richard E. Baldwin

Frederic Robert-Nicoud

Working Paper 10718

http://www.nber.org/papers/w10718

\author{
NATIONAL BUREAU OF ECONOMIC RESEARCH \\ 1050 Massachusetts Avenue \\ Cambridge, MA 02138
}

August 2004

The views expressed herein are those of the author(s) and not necessarily those of the National Bureau of Economic Research.

(C2004 by Richard E. Baldwin and Frederic Robert-Nicoud. All rights reserved. Short sections of text, not to exceed two paragraphs, may be quoted without explicit permission provided that full credit, including (C) notice, is given to the source. 
The Impact of Trade on Intraindustry Reallocation and Aggregate Industry Productivity: A Comment Richard E. Baldwin and Frederic Robert-Nicoud

NBER Working Paper No. 10718

August 2004

JEL No. H32, P16

\begin{abstract}
$\underline{\text { ABSTRACT }}$
Melitz (2003) demonstrates that greater trade openness raises industry productivity via a selection effect and via a production re-allocation effect. Our comment points out that the set-up assumed in the Melitz model displays a trade off between static and dynamic efficiency gains. That is, although freer trade improves industry productivity in a level sense, it harms it in a growth sense. To make this point as simply as possible, we introduce a slight modification to the model that endogenises the growth rate of industry productivity and we show that liberalisation slows growth.
\end{abstract}

Richard E. Baldwin

Graduate Institute of International Studies

Avenue de la Paix 11A

1202 Geneva, Switzerland

and NBER

baldwin@hei.unige.ch

Frederic Robert-Nicoud

Economics Department

University of Geneva

Boulevard du Pont Arve 40

1211 Geneva 4, Switzerland

robert@ecopo.unige.ch 


\title{
The impact of trade on intraindustry reallocations and aggregate industry productivity: a comment
}

\author{
Richard E. Baldwin and Frédéric Robert-Nicoud* \\ July 2004
}

\begin{abstract}
.
Melitz (2003) demonstrates that greater trade openness raises industry productivity via a selection effect and via a production re-allocation effect. Our comment points out that the set-up assumed in the Melitz model displays a trade off between static and dynamic efficiency gains. That is, although freer trade improves industry productivity in a level sense, it harms it in a growth sense. To make this point as simply as possible, we introduce a slight modification to the model that endogenises the growth rate of industry productivity and we show that liberalisation slows growth.
\end{abstract}

JEL H32, P16. Keywords: trade liberalisation, endogenous growth, heterogeneous firms, dynamic versus static efficiency.

\section{INTRODUCTION}

Until the 1980s, 'old' trade theory assumed away intra-industry trade for simplicity's sake, but empirical evidence revealed that the bulk of world trade was exactly of the assumed-away kind. In response, 'new' trade (Helpman and Krugman 1985) incorporated imperfect competition and increasing returns to account for intraindustry trade. The 'new' trade modelling approaches assumed away differences among firms for simplicity's sake, but empirical evidence has recently highlighted the fact that intra-firm differences are critical to understanding the data. In response, Melitz (2003) created one branch of the 'new new' trade theory by incorporating firm-level heterogeneity into general equilibrium trade models in a way that allows him to account for the main firm-level facts (also see Helpman, Melitz and Yeaple 2004, Eaton and Kortum 2002, Bernard, Eaton, Jensen and Kortum 2003, and Bernard, Jensen, and Schott, 2004).

\footnotetext{
* Baldwin; Graduate Institute of International Studies, Avenue de la Paix 11A, 1202 Geneva, Switzerland, http://heiwww.unige.ch/ baldwin, tel.+41 22 734-8950; fax:733-3049; Robert-Nicoud; Economics Department, University of Geneva, Boulevard du Pont d'Arve 40, 1211 Geneva 4, Switzerland, http://www.unige.ch/ses/ecopo/staff/robert/home.html, tel. +41 22 379-8272; fax: 379-8293.
} 
One of Melitz (2003)'s key result is to demonstrate that greater trade openness raises industry productivity via a selection effect (lowering the maximum marginal cost of active firms) and via a production re-allocation effect (production shifts to the most productive firms). Our comment points out that the Melitz model is subject to a trade off between static and dynamic productivity gains. In particular, although freer trade improves industry productivity in a level sense, it harms it in a growth sense. Thus, Melitz's positive openness-productivity correlation may hold within a sector for some time, but need not hold across sectors. If econometricians use cross-section variation to identify the openness-productivity relationship, the 'Melitz model' modified to allow for growth is consistent with a negative openness-sectoral-productivity correlation.

To make this point as simply as possible, we work with a slightly modified Melitz model in which both the level and growth of industry productivity are endogenous and affected by openness. The rest of our comment is organised in two sections. The next presents a brief re-statement of the Melitz model and the subsequent section presents a dynamic Melitz model and our main comment. Formal details of the dynamic model are in the appendix.

\section{THE MELITZ MODEL}

The Melitz model combines heterogeneity in firm's marginal costs with elements of the new trade theory (Helpman and Krugman 1985) and its extension to include market-entry costs (Baldwin 1988, Baldwin and Krugman 1989, and Dixit 1988). His goal is to characterise how industry competition and openness influence firms' export behaviour and the distribution of their productivity levels. Melitz (2003) works with identical nations, a single primary factor and a single consumption-good sector. He focuses on the steady state equilibrium and ignores discounting, but assumes firms face a constant probability of 'death' so present values remain finite (the hazard rate is $\delta$ ). The model is characterised by Dixit-Stiglitz monopolistic competition and iceberg trade costs (selling one unit in the export market requires shipment of $\tau \geq 1$ units). Marginal production costs are constant but increasing returns arise from three fixed costs paid just prior to production. All firms face the standard Dixit-Stiglitz fixed cost of developing a new variety, but selling their variety also requires them to pay fixed costs to enter each market. These fixed market-entry costs - or 'beachhead' costs - reflect the cost of introducing a new variety into a market, e.g. the cost of meeting market-specific standards and regulations, establishing a brand name, etc. These costs are denoted as $F_{D}$ and $F_{X}$ for the local and export markets, respectively; we impose $F_{X}>F_{D}$ in the focal case. 
Our slightly modified version of the Melitz model adopts all the above assumptions but assumes there are only two nations and that all three fixed costs are sunk.

\subsection{Equilibrium solutions and impact of freer trade}

Symmetry of nations equalises wages, so taking labour as numeraire wages are unity and all heterogeneity in firms' marginal costs stem from differences in firms' unit labour requirements, which are denoted as 'a'.

Standard Dixit-Stiglitz results tell us that a firm's operating profit, denoted as $\pi$, equals its sales times $1 / \sigma$ where $\sigma>1$ is the constant elasticity of substitution among varieties. Sales depend upon a firm's market share and this is inversely proportional to its marginal cost. By the standard logic of fixed costs, only firms with sufficiently low marginal costs will enjoy sales that justify the sunk market-entry costs. Focusing on steady states, the relevant comparison is between the present value of operating profit and the sunk market-entry costs. Given the constant firm-death rate, $\delta$, the present value is just $\pi / \delta$, so the cut-off levels of marginal cost are defined by:

$$
s\left[a_{D}\right] \frac{E}{\sigma \delta}=F_{D} ; \quad s\left[\tau a_{X}\right] \frac{E}{\sigma \delta}=F_{X}
$$

where $a_{D}$ and $a_{X}$ are the cut-off marginal costs for entering the local market and the export market, respectively, $\mathrm{E}$ is expenditure, and $\mathrm{s}[\cdot]$ is the Dixit-Stiglitz market share function:

$$
s[a]=\left(\frac{1}{n}\right) \frac{a^{1-\sigma}}{\Delta} ; \quad \Delta=\left(\int_{0}^{a_{D}} a^{1-\sigma} f[a] d a+\tau^{1-\sigma} \int_{0}^{a_{X}} a^{1-\sigma} f[a] d a ;\right.
$$

where $\mathrm{n}$ is the mass of active firms, $\Delta$ is Melitz's definition of average productivity $-\bar{\varphi}$ in his notation - as well as the denominator of the standard CES demand function, $\mathrm{f}[\mathrm{a}]$ is the distribution of firm's a's, $\mathrm{n}$ is the mass of active firms and $\tau>1$ is the iceberg trade cost. An intuitive interpretation of (2) is that a firm's market share deviates from $1 / \mathrm{n}$ to the extent its marginal cost, a, deviates from the average, $\Delta$. The two cut-off marginal costs define three types of varieties: Ntypes, D-type and X-type. Varieties with marginal costs greater than $\mathrm{a}_{\mathrm{D}}$ are non-producers $(\mathrm{N}-$ types), those with marginal costs less than ax enter both markets (X-types), and those with marginal costs between $\mathrm{a}_{\mathrm{D}}$ and $\mathrm{a}_{\mathrm{X}}$ enter only their domestic market (D-types).

I-sector. Standard new trade models assume firm-level productivity is identical across all firms, so there is no need to explicitly model its determination. The whole point of the Melitz model, however, is to endogenise the distribution of firm-level marginal costs, so he explicitly models the 
process by which new technologies are generated and selected. Melitz (2003) implicitly considers the development of new varieties as part of a firm's activity. However, intuition in served by treating variety development more explicitly. To this end, we introduce an artificial innovation sector (I-sector for short) and re-interpret the sunk costs. This re-interpretation entails no loss of generality in the static Melitz model, but that allows us to transition easily to a dynamic Melitz model in the next section.

The perfectly competitive I-sector makes and sells 'patents' for new varieties. I-firms first develop the fundamental knowledge behind a new variety and then, if warranted, they also invent the knowledge necessary to meet the market-entry costs, e.g. the knowledge necessary to adapt the variety to market-specific standards and regulations. In particular, creating a new variety requires $\mathrm{F}_{\mathrm{I}}$ units of knowledge, while adapting it to local and export market conditions requires $\mathrm{F}_{\mathrm{D}}$ units and $\mathrm{F}_{\mathrm{X}}$ units of knowledge, respectively.

Choosing units of knowledge carefully, and assuming constant returns in knowledge production, the F's can be taken as fixed costs measured in units of labour as in the Melitz model. Since our I-sector is Walrasian, we could equally well think of its activities as undertaken internally by manufacturing firms, as Melitz does.

Following Melitz (2003), the variety-innovation process is stochastic. Development of a new variety always requires $F_{I}$ units of knowledge, but it is stochastic in the sense that the marginal cost associated with the new variety - as measured by its associated ' $a$ ' - is drawn from a Pareto distribution whose the cumulative density function is: ${ }^{1}$

$$
G[a]=\left(\frac{a}{a_{0}}\right)^{k} \quad 0 \leq a \leq a_{0}
$$

where $\mathrm{k}$ and $\mathrm{a}_{0}$ are the 'shape' and 'scale' parameters, respectively; without loss of generality, we choose units such that $\mathrm{a}_{0}=1$. After developing a new variety, the I-sector firm checks the associated ' $\mathrm{a}$ ' to determine the variety's type. N-types are abandoned, but the innovator sinks a further $\mathrm{F}_{\mathrm{D}}$ for D-types and $\mathrm{F}_{\mathrm{D}}+\mathrm{F}_{\mathrm{X}}$ for $\mathrm{X}$-types. The patents are sold at competitive prices, namely the present value of the variety's operating profit. $^{2}$

\footnotetext{
${ }^{1}$ See Melitz (2003) for analysis with more general distributions.

${ }^{2}$ Given (1) and (2) these values are $\mathrm{v}_{\mathrm{N}}=0, \mathrm{v}_{\mathrm{D}}=\mathrm{a}^{1-\sigma} \mathrm{E} / \mathrm{n} \Delta \sigma \delta$, and $\mathrm{v}_{\mathrm{X}}=(1+\phi) \mathrm{a}^{1-\sigma} \mathrm{E} / \mathrm{n} \Delta \sigma \delta$ for a's in the appropriate ranges.
} 
Given (3) and the law of large numbers, I-firms face no aggregate uncertainty and produce the three types of varieties in constant proportions. ${ }^{1}$ The fraction of N-types is $1-G\left[a_{D}\right]$, where G[·]; the fractions of X-type and D-types are $G\left[a_{X}\right]$ and $G\left[a_{D}\right]-G\left[a_{X}\right]$, respectively. Given the frequency of the three types, a typical I-sector firm's pure profit is proportional to: ${ }^{2}$

$$
\Pi_{I}=\left(\frac{E}{n \sigma \delta}-\bar{F}\right)=0 ; \quad \bar{F} \equiv F_{D}+\frac{G\left[a_{X}\right] F_{X}}{G\left[a_{D}\right]}+\frac{F_{I}}{G\left[a_{D}\right]}
$$

where the first term in parentheses is the ex ante expected profit on a 'winning' variety, and $\bar{F}$ is the expected fixed cost of a 'winner'. ${ }^{3} \bar{F}$ consists of $\mathrm{F}_{\mathrm{D}}$ (for all winners) plus $\mathrm{F}_{\mathrm{X}}$ times the probability of an X-type (conditional on it being a winner) plus the expected development cost of getting a winner, which is $F_{I}$ times $1 / G\left[a_{D}\right]$. Free entry drives $\Pi_{I}$ to zero as indicated.

To replace the dying varieties, the I-sector produces a measure of new varieties equal to $\delta$, so Ifirms continually sample an infinite number of times from (3). By the law of large numbers and (3), the distribution of a's among active firms is therefore: ${ }^{1}$

$$
f[a]=k \frac{a^{k-1}}{a_{D}^{k}}
$$

Melitz (2003) shows that the lack of pure profits implies:

$$
E=L
$$

Note that the cut-off marginal costs are chosen to maximise I-sector profit but the mass of active firms per nation, $\mathrm{n}$, rises to eliminate ex ante pure profit in innovation. Thus, the three equilibrium variables, $a_{D}, a_{X}$ and $n$, are defined by the two cut-off conditions, (1), and the zero profit condition (4). Calculations are facilitated by solving $\Delta$ from (2) using (5) and (6), and identifying the ratio of cut-offs from (1) using (2). Thus:

$$
\Delta=\frac{\beta a_{D}^{1-\sigma}}{\beta-1}\left(1+\tau^{1-\sigma}\left(\frac{a_{X}}{a_{D}}\right)^{1-\sigma+k}\right) ; \quad \frac{a_{X}}{a_{D}}=\frac{1}{\tau}\left(\frac{F_{D}}{F_{X}}\right)^{\frac{1}{\sigma-1}} ; \quad \beta \equiv \frac{k}{\sigma-1}>1
$$

The regularity condition $\beta>1$ ensures that the integrals converge. Employing (7), the $a_{D}$ cut-off condition implies:

\footnotetext{
${ }^{1}$ We are dealing with a continuum of varieties, so the I-sector produces an uncountable infinity of varieties every period, so, by the Central Limit theorem, there is no aggregate uncertainty.

${ }^{2}$ Total sector profits are $\delta$ times $\Pi_{\mathrm{I}}$, since $\delta \mathrm{n}$ is the steady-state sectoral output.

${ }^{3}$ Total operating profit per nation is $\mathrm{E} / \sigma$, so the expected operating profit per firm, before ' $\mathrm{a}$ ' is known, is E/ $\sigma \mathrm{n}$.
} 
(8)

$$
n=\frac{L(\beta-1) / F_{D}}{\delta \sigma \beta(1+\Omega)} ; \quad 0 \leq \Omega \equiv \tau^{-k}\left(\frac{F_{X}}{F_{D}}\right)^{1-\beta} \leq 1
$$

where $\Omega$ (mnemonic for 'openness') measures the combined protective effects of higher exportmarket entry costs and iceberg trade costs $\left(\Omega=0\right.$ with infinite $\tau$ and/or $F_{X} / F_{D}, \Omega=1$ with free trade and $\left.\mathrm{F}_{\mathrm{X}}=\mathrm{F}_{\mathrm{D}}\right)$.

From (8), E/ $\sigma$ n $\delta$ equals $\beta \mathrm{F}_{\mathrm{D}}(1+\Omega) /(\beta-1)$, so the fact that $\mathrm{G}\left[\mathrm{a}_{\mathrm{X}}\right] / \mathrm{G}\left[\mathrm{a}_{\mathrm{D}}\right]$ equals $\left(\tau^{1 / 1-\sigma} \mathrm{F}_{\mathrm{D}} / \mathrm{F}_{\mathrm{X}}\right)^{\mathrm{k}}$ and $G\left[a_{D}\right]=\left(a_{D} / a_{0}\right)^{k}$ allow us to solve the zero profit condition $(4)$ for $a_{D}$. We get:

$$
a_{D}=\left(\frac{(\beta-1) F_{I} / F_{D}}{1+\Omega}\right)^{1 / k}, a_{X}=\left(\frac{\Omega(\beta-1) F_{I} / F_{X}}{1+\Omega}\right)^{1 / k}<a_{D}
$$

Here we have also used the solution for $a_{D}$ together with the solution for $a_{D} / a_{X}$ in (7) to get the solution for $\mathrm{ax}_{\mathrm{X}}$. A first main result of the Melitz model is:

\section{Result 1: Only some firms export; exporting firms are larger and have higher productivity.}

\subsection{Productivity effects of liberalisation}

A major finding of Melitz (2003) is that trade liberalisation raises industry productivity. His analysis focuses on average productivity expressed in physical units of output per unit of labour since all varieties are measured in the same units. Physical output cannot be added across varieties in most industries, so econometricians typically rely on measured productivity, namely the per worker value of a firm's output divided by a producer price index. Total sales and labour input per nation are $E$ and $L$ respectively, so the value of sales per worker is $E / L=1$ from (6) (by (4), the flow of operating profit exactly pays for I-sector labour needed to replace dying varieties). The producer price index for national firms is $n \int_{D}^{a_{D}}\left(a /(1-1 / \sigma)^{1-\sigma} f[a] d a\right.$ raised to the power of $1 /(1-\sigma)$. Solving the integral, measured labour productivity is the inverse of the price index, where this equals $\mathrm{a}_{\mathrm{D}}\left(\beta \mathrm{n} /(\beta-1)^{1 /(1-\sigma)}\right.$ times $(1-1 / \sigma)^{(\sigma-1)}$. Using $(9)$, measured labour productivity is:

$$
\text { avg measured productivity }=n\left(1-\frac{1}{\sigma}\right)^{\sigma-1}\left(\frac{1+\Omega}{(\beta-1) F_{I} / F_{D}}\right)^{1-1 / \beta}
$$

where $\mathrm{n}$ is given by (8). Since freer trade lowers $a_{D}$ and $n$, we have the main Melitz finding:

\section{Result 2: Freer trade raises an industry's average productivity level.}

This result also holds for a productivity measured in terms of physical units of output.

\footnotetext{
${ }^{1}$ See Melitz (2003) for a more formal proof.
} 


\section{Static Versus dynamic PROductivity gains: a dynamic Melitz MOdel}

Our main comment is that the set-up assumed in the Melitz model displays a trade off between static and dynamic efficiency gains under standard assumptions. That is, although freer trade improves industry productivity in a level sense, it harms it in a growth sense. To make this point as simply as possible, we introduce a slight modification to the model that endogenises the growth rate of industry productivity.

The only modification necessary concerns the assumption of constant returns in Melitz's innovation technology. More specifically, using our re-interpretation of Melitz's assumptions, we assume that knowledge generation is subject to a sector-wide learning curve, so that the marginal cost (in terms of labour) of knowledge falls as the cumulative output of knowledge rises. The assumed knowledge production function and learning curve are (see Grossman and Helpman 1991 and Romer 1990 for a justification based on knowledge spillovers):

$$
b_{I}=\frac{1}{n}
$$

where this assumes that the relevant cumulated learning is proportional to the stock of 'active' varieties (i.e. innovators gain cost-lowering experience only from 'winning varieties' and the relevance of the experience depreciates along with the varieties). Our results would carry through qualitatively even if we took the world stock of varieties, $2 \mathrm{n}$, or the stock of consumed varieties in a typical country, so we stick with (11) since it is standard in the endogenous growth literature.

Given (11), the average units of labour needed to developed an active variety is $b_{I} \bar{F}$, so with a constant death-rate of $\delta$, n grows according to (see appendix for details):

$$
g=L_{I} / \bar{F}-\delta
$$

where $\mathrm{g}$ is the growth rate of $\mathrm{n}$, and $\mathrm{L}_{\mathrm{I}}$ is I-sector employment, and $\bar{F}$ is defined in (4). Since $\mathrm{n}$ grows at the steady-state rate of ' $g$ ', operating profits of the average firms, namely E/ $\sigma$, fall at the rate $\mathrm{g}$. An income stream that falls at $\mathrm{g}$ and is discounted at $\delta$ has a present value of $\pi /(\delta+\mathrm{g}){ }^{1}$. Thus, the I-sector's free entry condition is (using (6) since it still holds):

$$
\Pi_{I}=\left(\frac{L}{n \sigma(\delta+g)}-b_{I} \bar{F}\right)=0
$$

\footnotetext{
${ }^{1}$ For example, the ex ante expected operating profit per variety is E/ $\sigma$ n; with $\mathrm{n}$ growing at $\mathrm{g}$ and a constant death probability of $\delta$, the present value is $\int^{-(\delta+g)}(E / \sigma n) d t$. Integrating from $t=0$ to infinity yields the result.
} 
Note that falling sunk costs have no impact on the cut-off points in (9) since all the sunk costs fall in tandem as the marginal cost of knowledge drops with learning. Also, note that $\mathrm{n}$ cancels out from the new free entry condition, (13), since $b_{I}=1 / n$. Thus, in the dynamic Melitz model the growth of $n$ rises to eliminate pure profits just as the level of $\mathrm{n}$ did in the static Melitz model. Solving (13):

$$
g=\frac{L}{\sigma \bar{F}}-\delta ; \quad \bar{F}=\frac{\beta F_{D}(1+\Omega)}{\beta-1}
$$

where we have used the equilibrium expressions for the cut-offs to simplify $\bar{F}$. By inspection of the expression for average measured productivity (10), average productivity grows at a rate of $\mathrm{g}$. To summarise, we write:

Result 3: Freer trade slows the growth rate of new varieties since it raises the expected fixed cost of an active variety, $b_{I} \bar{F}$, without affecting the expected reward. Consequently, average measured productivity grows more slowly.

The static versus dynamic productivity trade off is schematically illustrated in Figure 1.

\section{Figure 1: Static versus dynamic productivity effects of freer trade}

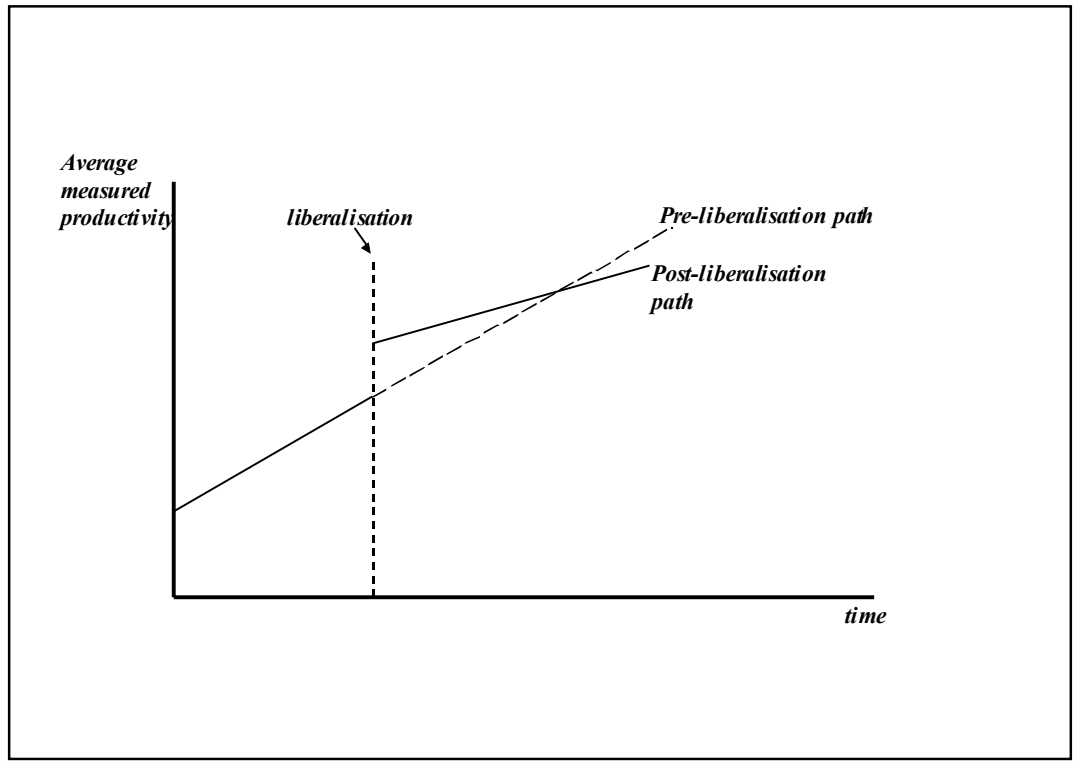

Note that if the econometrician can add physical units across varieties and defines average productivity as $\Delta$, then the growth rate of $\mathrm{n}$ has no effect on average productivity. In this case, the Melitz prediction holds without modification, even in the dynamic version.

\subsection{Extension to many sectors}

As is well know from Grossman and Helpman (1991), it is simple to put multiple sectors into this sort of dynamic model. If consumers have Cobb-Douglas preferences, and learning and trade costs 
are sector specific, each sector will have its own sector-specific growth rate. Given this, and Figure 1, there will be a tendency for the (historically) most closed sectors to be the most productive. Thus,

Result 4: The Melitz prediction of a positive correlation between openness and productivity levels may hold within an industry over time, but might not hold across sectors.

\section{REFERENCES}

Baldwin, Richard E. (1988). "Hysteresis in Import Prices: The Beachhead Effect," American Economic Review, 78, 4, pp 773-785.

Baldwin, Richard E. and Paul Krugman (1989). "Persistent Trade Effects of Large Exchange Rate Shocks," Quarterly Journal of Economics, pp 635-654, No. 419.

Bernard, Andrew, Jonathan Eaton, J. Bradford Jensen, and Peter Schott (2003). "Falling Trade Costs, Heterogeneous Firms and Industry Dynamics", mimeo, Tuck

Bernard, Andrew, J. Bradford Jensen, and Samuel Kortum (2003). "Plants and productivity in international trade", American Economic Review, 93, 4, 1268-1290.

Dixit, Avinash (1988). "Entry and exit decisions under uncertainty," Journal of Political Economy, 97, 4, pp 620-638.

Eaton, Jonathan and Samuel Kortum (2002). “Technology, Geography and Trade,” Econometrica, 70, 5, pp 1741-1780.

Grossman, Gene and Elhanan Helpman. (1991). Innovation and Growth in the World Economy. Cambridge, MA: MIT Press.

Helpman, Elhanan and Paul Krugman (1985), Market structure and Trade, MIT Press.

Helpman, Elhanan, Marc Melitz and Stephen Yeaple (2004). "Export versus FDI with heterogeneous firms," American Economic Review, 94, 1, pp. 300-317.

Melitz, M. (2003). "The impact of trade on intraindustry reallocations and aggregate industry productivity," Econometrica, 71, pp 1695-1725.

Romer, Paul (1990). “"Endogenous Technological Change," Journal of Political Economy, 98, S71S102. 


\section{Appendix A: The dYNAMIC MeLITZ MODEL}

This appendix presents and analyses the dynamic versions of the Melitz model more formally and more completely. The basic assumptions concerning the static economy are described in Section 2 of the main text.

\section{A.1 Extra assumptions}

As noted in the text, the only assumptions needed to make the Melitz model dynamic concern the innovation technology and these are introduced in the main text. Here we provide a fuller motivation.

Without loss of generality in the static model, we interpret the three fixed costs in the static Melitz model as involving units of knowledge capital that are created by an 'innovation sector' (I-sector). Specifically, the I-sector produces one unit of knowledge capital with $b_{I}$ units of $L$, so the marginal cost of a unit of knowledge is $b_{I}$. In the static model, $b_{I}=1$. In the dynamic model, $b_{I}$ is a parameter to individual I-firms, but it is generated by a sector-wide learning curve à la endogenous growth literature (Romer 1990, and Grossman and Helpman 1991). That is, the marginal cost of producing new knowledge declines as the sector's cumulative learning rises. Many justifications of this intertemporal externality are possible. Romer (1990), for instance, rationalizes it by referring to the non-rival nature of knowledge. Grossman and Helpman (1991) assert that it reflects the impact of 'public knowledge' that is created automatically along with the private, patentable knowledge. Here we assume that learning only occurs from 'winning' varieties, i.e. D-types and X-types, and that the relevance of the learning depreciates along with the knowledge capital itself, so the learning curve is $b_{l}=1 / n$ (i.e. the marginal cost of a developing a new variety falls as $n$ rises).

Given the learning curve, I-sector labour, $\mathrm{L}_{\mathrm{I}}$, produces a steady flow of new knowledge capital, with the flow equal to $\mathrm{L}_{\mathrm{I}} / \mathrm{b}_{\mathrm{I}}$. The corresponding flow of winning varieties is this flow divided by the average number of knowledge units per winning variety, namely $\bar{F}$ from (4). The change in the number of active varieties is the gross creation, $L_{I} / b_{I} \bar{F}$, less the depreciation loss, $\delta$, i.e.:

$$
\mathrm{g} \equiv L_{I} / \bar{F}-\delta
$$

where $\mathrm{g}$ is the growth rate of $\mathrm{n}$. Importantly, the learning curve in knowledge creation means that although the fixed costs in terms of units of knowledge, i.e. $\bar{F}$, are time-invariant, in terms of the numeraire, i.e. $b_{I} \bar{F}$ they fall at the rate that 'n' rises. 
We assume an infinitely lived representative consumer (in each country) with preferences:

$$
U=\int_{t=0}^{\infty} e^{-\rho t} \ln C d t ; \quad \mathrm{C}=\left(\int_{i \in \Theta} c_{i}^{1-1 / \sigma} d i\right)^{\frac{1}{1-1 / \sigma}}
$$

where $\rho$ is the rate of time preference, $\sigma$ is the constant elasticity of substitution among varieties, and $\Theta$ is the set of produced varieties. Utility optimisation yields demand functions and an optimal expenditure path that is characterised by a transversality condition and the standard Euler equation:

$$
\dot{E} / E=r-\rho
$$

where ' $\mathrm{r}$ ' is the rate of return on investment. Expenditure on goods equals income less investment in new knowledge capital, where income equals labour income L plus all operating profit $\mathrm{E} / \sigma$, and investment, in units of the numeraire, is $\mathrm{L}_{\mathrm{I}}$. Thus, we have:

$$
E=\frac{L-L_{I}}{1-1 / \sigma}
$$

\section{A.2 Choice of state variable and equilibrium calculations}

Although the equilibrium is unaffected by the choice of state variables, the ease of calculation depends greatly on this choice. We choose $\mathrm{L}_{\mathrm{I}}$ as the state variable. Given this, (15), (17) and (18), this choice implies that ' $\mathrm{g}$ ' and $\mathrm{E}$ will be time invariant in steady state and $\mathrm{r}=\rho$. This model has no transitional dynamics, so $\mathrm{g}, \mathrm{r}$ and $\mathrm{E}$ are always time invariant except perhaps just after parameter changes. To summarise, our choice of state variable implies:

\section{Result 5: Expenditure, $E$, the discount rate, $r$, and the growth rate of varieties, $g$, are all time- invariant along the steady state growth path.}

As we shall see, the growth rate rises up to the point where pure profit in innovation is eliminated, so the first step is to calculate the pure profit of an I-firm and this, in turn, requires us to pin down the cut-off levels of marginal cost. This was discussed in passing in the main text; here we review the determination of the cut-offs in more detail.

The present value of selling to the local market is:

$$
\int_{0}^{\infty}\left\{e^{-(\rho+\delta) t} \frac{s[a, t] E}{\sigma}\right\} d t \quad a_{D} \leq a \leq a_{X}
$$

since $\mathrm{e}^{-\rho t}$ reflects the classic discounting and $\mathrm{e}^{-\delta \mathrm{t}}$ is the probability that the variety is still alive at $\mathrm{t}$ given the Poisson firm-death process; $\Delta$ is time invariant, but $\mathrm{s}[\mathrm{a}]$ depends upon time since $\mathrm{n}$ does. Specifically: 


$$
s[t ; a]=\left(\frac{1}{n[t]}\right) \frac{a^{1-\sigma}}{\Delta} ; \quad \Delta=\frac{\beta a_{D}{ }^{1-\sigma}}{\beta-1}\left(1+\phi\left(\frac{a_{X}}{a_{D}}\right)^{1-\sigma+k}\right) ; n[t]=n_{0} e^{g t}
$$

Since $\mathrm{n}$ grows at the rate of ' $\mathrm{g}$ ', the time integral is trivial to solve.

Simplifying and performing similar calculations for the present value for exporting, the D-type and X-type cut-off conditions are almost identical to those in the static model, (1), with the discount rate equal to $\delta+\rho+g$ instead of just $\delta$. Specifically:

$$
\frac{s\left[a_{D}\right] E / \sigma}{\delta+\rho+g}=b_{I} F_{D} ; \quad \frac{s\left[\tau a_{X}\right] E / \sigma}{\delta+\rho+g}=b_{I} F_{X}
$$

where s[a] is defined as in (19). Importantly, both the left-hand and right-hand sides of both cut-off conditions involve 1/n, so the level of n cancels out. From Result 5 all other elements are timeinvariant, so the cut-off levels of marginal cost, $\mathrm{a}_{\mathrm{D}}$ and $\mathrm{a}_{\mathrm{X}}$, are time invariant along the steady state growth path. To summarise:

\section{Result 6: The cut-offs, $a_{D}$ and $a_{x}$, are time invariant along the steady state growth path.}

Next, we turn to calculating the present value of new varieties. An I-firm that has sunk $b_{I} F_{I}$ units of labour to develop a new variety will inspect the associated ' $a$ ' and invest a further $b_{I} F_{D}$ or $b_{I}\left(F_{X}+F_{X}\right)$ in order to maximise the value of its innovation. Specifically, if the associated marginal cost is too high $\left(a>a_{D}\right)$, the variety is dropped; if $a_{D}>a>a_{X}$ only $b_{I} F_{D}$ is invested, and if $a<a_{X}$ then $b_{I}\left(F_{X}+F_{X}\right)$ is invested. The value of the resulting variety as a function of its associated marginal cost is:

$$
\begin{array}{ll}
v_{N}=0 & a_{D}<a \\
v_{D}[a]=\frac{a^{1-\sigma} E}{\sigma \Delta(\delta+\rho+g)} & a_{D} \leq a \leq a_{X} \\
v_{X}[a]=\frac{(1+\phi) a^{1-\sigma} E}{\sigma \Delta(\delta+\rho+g)} & a \leq a_{X}
\end{array}
$$

where $\Delta$ is defined by (19). Intuition is served by noticing that the ex ante expected present value of a 'winning' variety is much simpler. Total operating profit per period per market per firm is just $\mathrm{E} / \mathrm{n} \sigma$. This falls at a rate of $\mathrm{g}$, is discounted at a rate of $\rho$ and dies with a probability of $\delta$, so the present value of a winner is $\mathrm{E} / \mathrm{n} \sigma(\delta+\rho+\mathrm{g})$. Pure profit per 'winner' thus equals this present value less the expected fixed cost necessary to get a winner, which in terms of the numeraire is:

$$
b_{I} \bar{F} \equiv b_{I}\left(F_{D}+\left(\frac{a_{X}}{a_{D}}\right)^{k} F_{X}+\left(\frac{a_{0}}{a_{D}}\right)^{k} F_{I}\right)
$$


given (3). The cut-off marginal costs are chosen to maximise I-sector profit but the growth rate of active firms per nation, g, rises to eliminate ex ante pure profit in the innovation sector. The zero Isector profit condition is:

$$
\Pi_{I}=\left(\frac{E / \sigma}{n(\delta+\rho+g)}-b_{I} \bar{F}\right)=0
$$

The three equilibrium variables, $\mathrm{a}_{\mathrm{D}}, \mathrm{a}_{\mathrm{X}}$ and $\mathrm{g}$, are defined by the two cut-off conditions, (20) and the zero profit condition (23). As in the static model, calculations are facilitated by identifying the ratio of cut-offs from (20):

$$
\frac{a_{X}}{a_{D}}=\frac{1}{\tau}\left(\frac{F_{D}}{F_{X}}\right)^{\frac{1}{\sigma-1}} \leq 1 ; \beta \equiv \frac{k}{\sigma-1}>1
$$

We find $\mathrm{a}_{\mathrm{D}}$ from the zero profit condition (23) by noting that from (20), (19) and (24), E/ $\sigma \mathrm{n}(\delta+\rho+g)$ equals $\beta b_{1} F_{D}(1+\Omega) /(\beta-1)$, and using (24) in the expected fixed cost in (22), we can isolate $a_{D}$ since $G\left[a_{D}\right]=\left(a_{D} / a_{0}\right)^{k}$. Solving and simplifying, and recalling our normalization $a_{0}=1$, we get:

$$
a_{D}=\left(\frac{(\beta-1) F_{I} / F_{D}}{1+\Omega}\right)^{1 / k}
$$

This is identical to $a_{D}$ in the static Melitz model. Using this and (24), we see that the formula for $a_{X}$ is also identical to that of the static Melitz model.

The equilibrium growth rate of $\mathrm{n}$ is solved from (23) using our solutions for $\mathrm{a}_{\mathrm{D}}$ and $\mathrm{a}_{\mathrm{X}}$, this yields:

$$
g=\frac{E}{\sigma \bar{F}}-\delta-\rho ; \quad \bar{F}=\frac{\beta F_{D}(1+\Omega)}{\beta-1}
$$

All that is left is the calculation of the steady state E. As noted above, expenditure equals labour income plus operating profit minus $\mathrm{L}_{\mathrm{I}}$. From (23), total operating profit equals $(\delta+\rho+g) \bar{F}$ and from (15) we have $\mathrm{L}_{\mathrm{I}}$ equals $(\delta+g) \bar{F}$, thus we can write:

$$
E=L+\rho n b_{I} \bar{F}
$$

In other words, steady state expenditure equals 'permanent income' -labour income plus the interest earned on 'equity'. To see this, note that $b_{I} \bar{F}$ is the average value of an active variety (due to zero profit in the I-sector), so $n$ times this is the value of the stock market $\left(\mathrm{NB}, \mathrm{nb}_{\mathrm{I}}=1\right)$ and $\rho$ times this is the required reward for having postponed consumption. The static Melitz model ignores discounting, i.e. sets $\rho=0$, so consumers/investors do not need to be compensated for foregone 
consumption and $\mathrm{E}=\mathrm{L}$. With this, (27) confirms the expression in the main text, (14). In the more standard case of $\rho>0$, $g$ is still diminishing in openness since $\bar{F}$ is more important in the denominator of (26), and $\bar{F}$ rises as trade gets freer, i.e. as $\phi$ rises. 